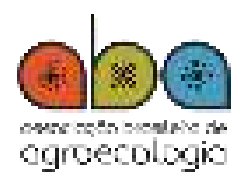

ISSN: $1980-9735$

\title{
AVALIAÇÃO DO REAPROVEITAMENTO DE RESÍDUOS VEGETAIS NA PRODUÇÃO DE ALFACE, VISANDO O AUMENTO DE ATRIBUTOS BIOMÉTRICOS
}

Evaluation of the reusing of plant residues in lettuce production with increasing

biometric attributes

\author{
Kleber Lopes Longhini ${ }^{1}$, Rafael Egea Sanches ${ }^{2}$, Anny Rosi Mannigel ${ }^{2}$ e Eduardo Soares ${ }^{3}$ \\ RESUMO
}

O estudo teve o objetivo de avaliar o efeito de materiais de cobertura do solo em área de produção de alface. $O$ delineamento experimental foi de blocos casualizados com cinco repetições. Os tratamentos constaram de casca de arroz, casca de café, palha de braquiária, palha de aveia branca e testemunha. Avaliou-se umidade do solo, temperatura abaixo da cobertura, desenvolvimento radicular, circunferência de planta, peso bruto e peso comercial. Sem cobertura vegetal, o solo apresentou maior temperatura e menor umidade $\left(19,8{ }^{\circ} \mathrm{C}\right.$ e $\left.69,39 \%\right)$. A utilização de casca de café proporcionou maior circunferência e peso das plantas $(78,6 \mathrm{~cm}$ e $0,459 \mathrm{~g})$. Conclui-se que a utilização de coberturas vegetais durante o cultivo da alface favorece o crescimento fenológico da cultura.

Palavras-chave: Agroecologia; Hortaliças; Nutrientes; Temperatura; Umidade.

1 Mestrando, Programa de Pós Graduação em Melhoramento Genético de Plantas - Universidade Estadual de Maringá - UEM. Email:

kleberlonghini@hotmail.com.br

${ }^{2}$ Professor, Centro de Ciências Exatas e Agrárias - Centro Universitário de Maringá - Unicesumar. Email:

armannige!@gmail.com;

Rafael.sanches@unicesumar.br

${ }^{3}$ Engenheiro Agrônomo, Centro Universitário de Maringá - Unicesumar. Email: Eduardo.soares@hotmail.com

Recebido em:

21/05/2019

Aceito para publicação em:

08/10/2019

Correspondência para:

kleberlonghini@hotmail.com.br

\section{ABSTRACT}

The objective of this study was to evaluate the effect of soil cover materials on lettuce production. The experimental design was randomized blocks with five replications. The treatments consisted of rice husk, coffee husk, brachiaria straw, white oat straw and control. Soil moisture, temperature below cover, root development, plant circumference, gross weight and commercial weight were evaluated. Without vegetal cover, the soil presented higher temperature and lower humidity $\left(19.8{ }^{\circ} \mathrm{C}\right.$ and $\left.69.39 \%\right)$. The use of coffee husk provided greater circumference and plant weight $(78.6 \mathrm{~cm}$ and $0.459 \mathrm{~g})$. It can be concluded that the use of vegetable mulches during lettuce cultivation favors the phenological growth of the crop.

Keywords: Agroecology; Moisture; Nutrients; Temperature; Vegetables. 
A alface (Lactuca sativa L.) é hortaliça anual, da família Asteraceae, sendo considerada a hortaliça folhosa mais importante na alimentação brasileira, devido a sua composição nutricional (BORCIONI, 2008). Por ser consumida in natura, a alface conserva suas propriedades nutritivas e de ser excelente fonte de vitaminas e sais minerais (MOTA et al., 2012). O sabor, a facilidade de aquisição e produção durante o ano todo, o que resulta em um baixo custo para o consumidor final são aspectos favoráveis aos cultivo da alface (OLIVEIRA et al., 2004; COMETTI et al., 2004). No Brasil, o plantio da alface tem ocupado área em torno de 35.000 hectares, somando a produção intensiva com produtores familiares, e gerando mais de cinco empregos por hectare (SOUSA et al., 2014).

O processamento de produtos oriundos da agroindústria gera grande volume de resíduos orgânicos e ocasiona pendências ambientais decorrentes do seu acúmulo e despejo em locais inapropriados. No entanto, os subprodutos gerados apresentam grande potencial a ser explorado, devido aos seus elevados teores nutricional (NASCIMENTO FILHO e FRANCO, 2015). De acordo com Jerônimo e Silva (2012), tais resíduos constituem excelentes matérias-primas para produção de substratos e adubos orgânicos de grande importância agronômica, social e econômica, proporcionando um acréscimo da produção e na melhoria da qualidade dos alimentos.

Nos últimos anos, diversas técnicas de cultivo de hortaliças vêm sendo desenvolvidas para aperfeiçoar o processo produtivo da alface, tal como o uso de restos vegetais sobre o solo, buscando oferecer melhores condições à planta, a fim de melhorar a produtividade da cultura e contribuir para conservação do meio ambiente (BLIND e SILVA, 2015). Os tipos de cobertura variam entre materiais orgânicos vegetais e filmes de polietileno, sendo explorados com vários objetivos, dentre eles, destacam-se: permitir o controle de plantas invasoras; oferecer proteção aos frutos, evitando seu contato direto com o solo; maior precocidade da colheita e capacidade de influir diretamente sobre a incidência de pragas e doenças (CASTOLDI, 2006). Pode-se, também, citar a redução da evaporação de água na superfície do solo e a diminuição das oscilações de temperatura do solo (KOSTERNA et al., 2014).

O objetivo deste trabalho foi avaliar o efeito de quatro tipos de coberturas vegetais sobre o crescimento fenológico da cultura da alface.

O estudo constou foi realizado no município de Itambé-PR, localizado na latitude $23^{\circ} 42^{\prime} 38.90^{\prime \prime} \mathrm{S}$ e longitude $51^{\circ} 40^{\prime} 48.25^{\prime \prime} \mathrm{O}$, e altitude de 794 metros com pluviosidade média anual de $1485 \mathrm{~mm}$. Segundo Köppen e Geiger, a classificação do clima da região é Cfa, sendo um clima temperado úmido com temperatura média anual de $18.3{ }^{\circ} \mathrm{C}$ (KOPPEN e GEISER 1928). O solo foi caracterizado como Latossolo-vermelho distrófico, de textura argilosa (SANTOS et al., 2018).

O experimento foi desenvolvimento entre os meses de agosto a novembro de 2018, cuja média de temperatura e de precipitação durante o experimento foi de $28{ }^{\circ} \mathrm{C}$ e $61 \mathrm{~mm}$, respectivamente (CLIMATEMPO, 2018). O preparo do solo foi realizado de forma convencional, através do trator Massey Ferguson $4 \times 4,75 \mathrm{cv}$, com a utilização de gradagem e enxada rotativa com encanteirador 115-200 BC-FC, MEC-RUL ${ }^{\circledR}$, largura entre ponteira 1,50m e altura do canteiro $0,25-0,45 \mathrm{~m}$.

A amostragem de solo para análise foi realizada nas profundidades de $0,1-0,2 \mathrm{~m}$, que orientou a adubação orgânica e uma adubação mineral complementar para cada parcela com o objetivo de fornecer as exigências nutricionais para a cultura se desenvolver com base na recomendação técnica Embrapa (1997). A adubação orgânica foi de $15 \mathrm{~kg}$ de esterco bovino por parcela, que apresenta em sua composição $1 \%$ de $\mathrm{N}$ e a adubação mineral foi de $50 \mathrm{~g}$ de sulfato de amônia, $15 \mathrm{~g}$ de super simples e $10 \mathrm{~g}$ de cloreto de potássio por parcela.

A variedade de alface utilizada foi Vanda, apresentando folhas grandes e crespas, de textura macia e consistente, sem formação de cabeça e de coloração verde. As mudas foram adquiridas em viveiro devidamente certificado, sendo caracterizadas por apresentarem $5 \mathrm{~cm}$ de altura e 4 folhas bem definidas. Essas mudas foram implantadas obedecendo à recomendação técnica da cultura (EMBRAPA, 2006) com o espaçamento de $0,25 \mathrm{~m}$ entre as plantas e $0,30 \mathrm{~m}$ entre as linhas do canteiro.

Os tratamentos consistiram de cinco coberturas vegetais sobre o solo cultivado: $\mathrm{T} 1$ = Casca de Café (Coffea arabica), contendo 5\% de $\mathrm{CO}$ e 3\% de N; T2 = Casca de Arroz (Oriza sativa), contendo 3\% de $\mathrm{CO}$ e $1 \%$ de N; 33 = Palha de aveia (Avena sativa L.), contendo $3 \%$ de CO; T4 = Palha de braquiaria 
(Brachiaria brizantha), contendo 4\% de CO e T5 = Testemunha, sem cobertura vegetal. 0 delineamento experimental foi em blocos inteiramente casualizados, contendo cinco repetições, sendo cada parcela composta por 10 plantas de alface.

Os vegetais utilizados como tratamentos foram submetidos ao seguinte processo de compostagem, antes da realização do respectivo experimento: foram fracionados a partículas de $5 \mathrm{~cm}^{3}$, enleirados e mantidos cobertos por lona durante 60 dias antes da realização do experimento. A cada 15 dias esses materiais eram revolvidos e, após os 60 dias, apresentaram teor de umidade de $7 \%$.

O sistema de irrigação usado no experimento foi do tipo aspersão com quatro (4) aspersores Agropolo ${ }^{\circledast}$ modelo $\mathrm{Ny} 30^{\circ}$, com bico do tipo longo verde ER 5,00 x 4,60 mm com encaixe de 1 polegada com pressão de trabalho de 20 a $45 \mathrm{mca}$. Espaçados em $12 \mathrm{~m}$ entre aspersor na linha e $12 \mathrm{~m}$ entre linhas, resultando em 2,17 a $3,26 \mathrm{~m}^{3} /$ hora para cada aspersor, totalizando a média de $10,84 \mathrm{~m}^{3} /$ hora de água nos canteiros, distribuído em dois horários de 30 minutos cada, nos períodos da manhã e à tarde.

As coberturas foram acondicionadas nos canteiros um dia após o plantio das mudas, em uma densidade de $0,05 \mathrm{~m}$ de altura para cada parcela. A cada sete dias, ao meio dia, foi realizada a mensuração da umidade e da temperatura do solo abaixo da cobertura, totalizando oito mensurações até o final do ciclo da cultura de, aproximadamente, 56 dias. A análise de temperatura do solo foi realizada com um medidor de temperatura infravermelho Benetech ${ }^{\circledR}$ e mod. GM 300, em três pontos aleatórios de cada parcela, sempre abaixo de cobertura vegetal. A análise de umidade do solo foi feita com um aparelho da marca/modelo BOND-TERRA na profundidade de 0-10 cm também em três pontos, da mesma forma que a temperatura.

A colheita foi realizada 55 dias após o transplante das mudas, sendo as plantas cortadas logo abaixo das folhas basais, bem próximas ao solo. Realizou-se a pesagem das plantas, antes da retirada das folhas basais, obtendo-se, assim, o peso bruto e, após a retirada destas folhas, obtendo-se o peso comercial. Determinou-se a circunferência das plantas por meio da medição com fita métrica e aleatoriamente foram tomadas três plantas de alface de cada parcela, a fim de medir-se o comprimento das raízes.

Com o uso do programa SISVAR (FERREIRA, 2011), comparou-se os efeitos dos tratamentos sobre o desenvolvimento da cultura da alface, realizando-se, inicialmente, a análise de variância dos dados $(p<0,05)$ e, para as variáveis que apresentaram diferenças significativas pelo teste $F$, aplicou-se o teste de Scott Knott a 5\% de probabilidade (BANZATTO e KRONKA, 2006). Os resultados mostraram as coberturas ao solo interferem na temperatura e umidade no cultivo da alface (Figura 1)

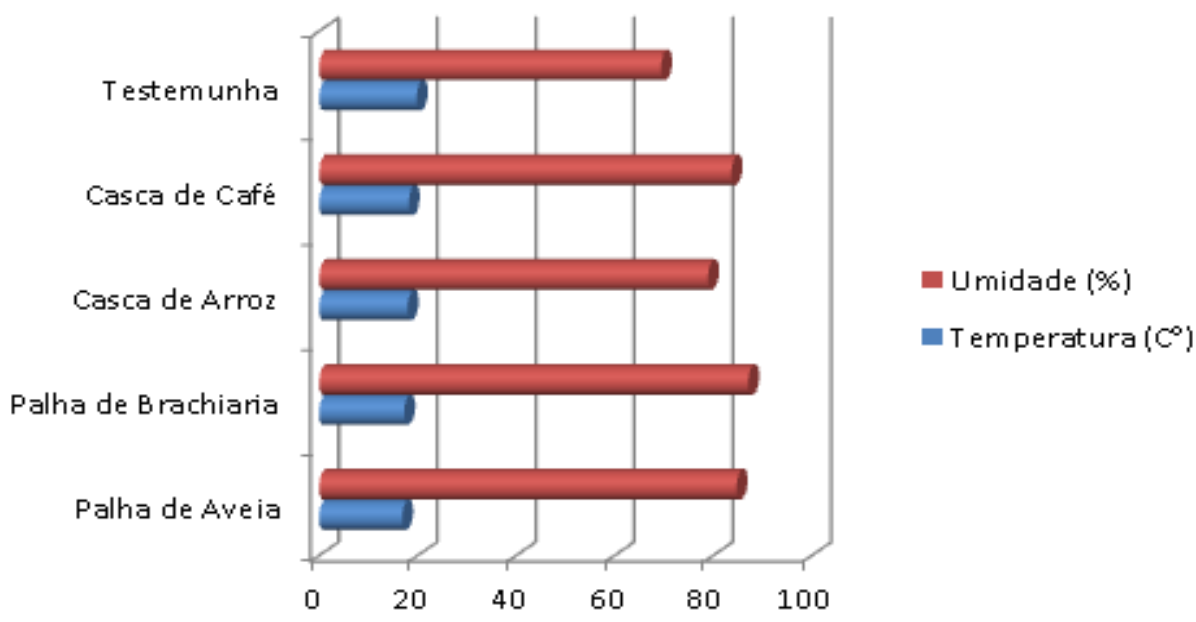

Figura 1: Temperatura e Umidade média semanal do solo cultivado com alface crespa sob diferentes coberturas vegetais.

O tratamento com a temperatura mais elevada foi sem cobertura vegetal (testemunha), com $19,8^{\circ} \mathrm{C}$ (Figura 1). Os tratamentos com maior redução da temperatura foram as palhas de aveia e de brachiaria, que apresentaram $16,84^{\circ} \mathrm{C}$ e $17,23^{\circ} \mathrm{C}$, respectivamente. Os mesmos tiveram coberturas que proporcionaram maior teor de umidade do solo, $84,7 \%$ e $87,08 \%$, respectivamente. 
De acordo com Pereira et al. (2002), as coberturas sobre o solo interceptarem a radiação solar de forma eficiente. Entre as principais características que favorecem esta interceptação, tem-se a alta refletividade de radiação solar e baixa condutividade térmica das palhadas de aveia e brachiaria (SILVA et al., 2006). De acordo com Streck et al. (1994), a aplicação de cobertura na superfície do solo tem sido utilizada para preservar a umidade e temperatura do solo, além de favorecer a atividade microbiana.

As cascas de arroz e de café proporcionaram resultados significativamente maiores em comparação à testemunha para reduzir a temperatura do solo e aumentar o teor de umidade, segundo Vieira (1988). Esse fato se dá devido às partículas físicas depositadas sobre o solo que impedem os raios solares infiltrem diretamente no perfil e contribuam para a elevação de temperatura. Kunz et al. (2002) pesquisando sobre o feijoeiro, mostraram que os restos vegetais atuaram como isolante térmico, impedindo que o solo se aquecesse e transmitisse calor para a profundidade de $0,1 \mathrm{~m}$, reduzindo, desse modo, a amplitude. Knies (2010), em estudo sobre a influência da cobertura do solo com resíduos vegetais de aveia preta, verificou que houve uma redução da temperatura no solo em até $6,27^{\circ} \mathrm{C}$, em relação a um solo descoberto, resultados que corroboram com os valores obtidos neste estudo. De acordo com Caliman et al., (2005) em relação à temperatura do solo, valores mais constantes e com menos variação proporcionados pelo uso de coberturas mortas sobre o solo, estimulam e aumentam a velocidade das reações bioquímicas, resultando em crescimento e desenvolvimento das plantas. A influência dos tratamentos sobre as plantas de alface é apresentada na Tabela 1.

Tabela 1: Avaliação da circunferência média da cabeça, comprimento da raiz, peso bruto médio e peso comercial médio da cultura do alface sob diferentes coberturas vegetais.

\begin{tabular}{|c|c|c|c|c|}
\hline Tratamentos & $\begin{array}{l}\text { Circunferência media } \\
\text { da cabeça }(m)\end{array}$ & $\begin{array}{l}\text { Comprimento médio da } \\
\text { raiz }(\mathrm{m})\end{array}$ & Peso bruto médio (kg) & $\begin{array}{l}\text { Peso comercial } \\
\text { médio }(\mathrm{kg})\end{array}$ \\
\hline Aveia & $0,6723 \mathrm{~b}$ & $0,12223 \mathrm{a}$ & $0,277 \mathrm{~b}$ & $0,222 c$ \\
\hline Braquiária & $0,6553 \mathrm{~b}$ & 0,11881 a & $0,307 b$ & $0,246 c$ \\
\hline Arroz & $0,6917 \mathrm{~b}$ & $0,13191 \mathrm{a}$ & 0,411 a & 0,333 a \\
\hline Café & $0,7860 \mathrm{a}$ & $0,12724 a$ & 0,459 a & 0,363 a \\
\hline Testemunha & $0,7130 \mathrm{~b}$ & $0,13224 a$ & $0,370 \mathrm{~b}$ & $0,303 \mathrm{~b}$ \\
\hline CV (\%) & 5,82 & 13,76 & 14,01 & 14,11 \\
\hline
\end{tabular}

Valores seguidos da mesma letra na coluna, não diferem entre si pelo teste Scott-Knott (1974), a 5\% de probabilidade.

Em relação à circunferência da cabeça das plantas de alface, apenas a casca de café obteve diferença significativa $(0,786 \mathrm{~m})$ em relação aos demais tratamentos (Tabela 1$)$. Esse resultado pode ter sido proporcionado devido à composição química da casca de café, que apresenta $5 \%$ de carbono orgânico 3\% e nitrogênio, valores esses superiores aos dos demais tratamentos utilizados.

Bernardino et al. (2005) relata de que, embora os teores nutricionais presentes na casca de café sejam variáveis, elementos minerais como cálcio, potássio, fósforo, magnésio, nitrogênio e carbono estão presentes em sua composição, nutrientes os quais são essenciais, não somente para o desenvolvimento da alface, mas como de todos vegetais.

Quanto às características físicas dos tratamentos, tanto o café quanto o arroz eram compostos apenas pelo envoltório da semente (cascas), suas partículas possuem cerca de $2 \mathrm{~cm}^{3}$, enquanto a aveia e a braquiária eram compostos pela palhada da planta, suas partículas possuem cerca de $5 \mathrm{~cm}^{3}$. Segundo Troeh e Thompson (2007), quanto menor o tamanho da partícula vegetal, maior sua área superficial específica e maior a superfície de contato.

No que diz respeito ao comprimento das raízes, não houve diferença significativa entre os tratamentos realizados, mediante o fato de que houve irrigação sobre o experimento que proporcionou água em quantidade suficiente para as plantas se desenvolverem. De acordo com Taiz et al. (2017), em solos que apresentam baixos teores de umidade, a planta tende a desenvolver o seu sistema radicular em profundidade com o intuito de encontrar água. Souza e Pereira (2011), utilizando coberturas mortas no cultivo de cenoura, também não encontraram alteração no número, o peso total e comercial de raízes, atribuindo ao fato do sistema de cultivo ser irrigado periodicamente, resultados esses que foram semelhantes aos encontrados no trabalho. 
De acordo com relatos de Souza e Resende (2006), o emprego de cobertura morta em períodos chuvosos auxilia, principalmente, no controle da erosão e proteção do solo, enquanto a utilização da cobertura em períodos secos do ano proporciona melhores efeitos sobre o desenvolvimento das hortaliças, pela retenção de umidade no solo e disponibilização de nutrientes.

No que diz respeito ao peso médio bruto e peso médio comercial das plantas de alface, as coberturas vegetais de casca de café e de arroz apresentaram diferença significativa em comparação com os demais tratamentos.

No momento em que as cascas de café ( $5 \%$ de Carbono Orgânico e 3\% de Nitrogênio) e de arroz (3\% de Carbono Orgânico e 1\% de Nitrogênio) sofrem o processo de decomposição, esses materiais liberam no solo nutrientes que são utilizados pelas plantas de alface para se desenvolverem, permitindo, assim, um aumento de peso na planta (MALAVOLTA, 2006).

Além disso, outra condição que favoreceu o aumento de peso das plantas que possuíam como coberturas vegetais as cascas de café e de arroz, foi o tamanho dessas partículas sob o solo, em torno de $2 \mathrm{~cm}^{3}$, que aceleram o processo de decomposição do material vegetal (BRADY e WEIL, 2013).

Os tratamentos da aveia e braquiária não apresentaram diferença significativa comparada à testemunha para nenhuma das variáveis comerciais analisadas. Esse fato pode ser explicado por tais coberturas vegetais possuírem maior tamanho de partícula, em torno de $5 \mathrm{~cm}^{3}$. Levando em consideração que foram aplicadas em forma de palha utilizando a planta inteira, isso contribuiu para lenta decomposição da matéria orgânica e menor liberação de nutrientes no solo quando comparado com as cascas de arroz e café. Outro fato é o elevado teor de lignina presente nessas plantas. Segundo Fukushima et al. (2000), a planta de aveia pode apresentar em sua composição vegetal até $29 \%$ de lignina e a braquiária 21\%. De acordo com Kiehl (1985), a lignina é um dos materiais considerados como os mais resistentes à decomposição de microrganismos, logo, os materiais vegetais que apresentam altas quantidades de lignina em sua composição química são decompostos de maneira mais lenta.

A adoção da técnica de cobertura vegetal mostrou ser viável, economicamente, para produção de alface, elevando os atributos biométricos da cultura, além de preservar o teor de umidade e temperatura do solo. Recomenda-se a utilização da casca de café. Com a utilização de resíduos vegetais na cultura da alface, o agricultor tem adubo orgânico com redução dos custos e ganhos ambientais.

\section{Referencias}

BANZATTO, David Ariovaldo; KRONKA, Sérgio do Nascimento. Experimentação agrícola. 4. ed. Jaboticabal: Funep, $237 \mathrm{p}, 2008$.

BERNARDINO, F. S.; et al. Produção e Características do Efluente e Composição Bromatológica da Silagem de Capim-Elefante Contendo Diferentes Níveis de Casca de Café. Revista Brasileira de Zootecnia, v.34, n.6, p. 21852191, 2005.

BLIND A. D.; SILVA FILHO D. F. Desempenho de cultivares de alface americana cultivadas com e sem mulching em período chuvoso da Amazônia. Revista Agro@mbiente On-line, v. 9, n. 2, p. 143-151, 2015.

BRADY, N. C; WEIL, R. R. Elementos da natureza e propriedades

dos solos. 3. ed. Porto Alegre: Artmed, 716 p, 2013.

CALIMAN, F. R. B.; et al. Avaliação de genótipos de tomateiro cultivados em ambiente protegido e em campo nas condições edafoclimáticas de Viçosa. Horticultura Brasileira, v. 23, p. 255-259, 2005.

CASTOLDI, R.; et al. Effect of plastic film mulch on the production of butterhead lettuce cultivars under protected cultivation. Acta Horticulturae, v. 67, p. 205, 2006.

CLIMATEMPO, Estação metereleológica do Paraná. https://www.climatempo.com.br/climatologia/278/maringapr. Acesso em 25/05/2019.

EMBRAPA. Como plantar hortaliças. Abc da agricultura familiar, Brasília, v. 1, n. 3, p. 1-27, fev./2006.

FERREIRA, D.F. Sisvar: A computer statistical analysis system. Ciência e Agrotecnologia (UFLA), v.35, n.6, p. 10391042, 2011.

FUKUSHIMA, R. S.; et al. Extração da Lignina e Emprego da Mesma em Curvas de Calibração para a Mensuração da Lignina. Revista Brasileira de Zootecnia, 2000.

KIEHL, E. J. Fertilizantes orgânicos. São Paulo,SP: Agronômica Ceres, 1985.

KNIES, A. E. Temperatura e umidade de um solo franco arenoso cultivado com milho. 2010, $104 \mathrm{f}$, Universidade Federal de Santa Maria, Santa Maria, 2010. 
KOSTERNA E. Soil mulching with straw in broccoli cultivation for early harvest. Journal of Ecological Engineering, v. 15, n. 2, p. 100-107, 2014.

KUNZ, M. et al. Temperatura do solo influenciado pelo sistema de manejo dado ao solo para a cultura do feijoeiro. Cuiabá: Sociedade Brasileira de Ciência do Solo, 2002.

MALAVOLTA, E. Manual de nutrição mineral de plantas. São Paulo-SP: Editora Agronômica Ceres, 638 p, 2006.

MOURA FILHO E. R.; et al. Efeito da cobertura do solo na produtividade da alface. Revista Brasileira de Agroecologia, v. 4, n. 2, p. 161-164, 2009.

NASCIMENTO FILHO, W.B.; FRANCO, C.R. Avaliação do potencial dos resíduos produzidos através do processamento agroindustrial no Brasil. Revista Virtual de Química, v. 7, n. 6, p. 1968-1987, 2015.

PEREIRA, A. R.; et al. Agrometeorologia: fundamentos e aplicações práticas. Guaíba: Agropecuária, 2002.

SANTOS, H.G.; et al. Sistema Brasileiro de Classificação dos solos. Embrapa, 5 ed, 2018.

SILVA, A. C.; COSTA, A. S. V. Decomposição de partes vegetativas de eucalipto submetidas a extratos de diferentes solos. Revista Acadêmica: ciências agrárias e ambientais, Curitiba, v. 2, n. 2, p. 11-20, abr./jun. 2004.

SILVA, V. R.; et al. Variação na temperatura do solo em três sistemas de manejo na cultura do feijão. Revista Brasileira de Ciência do Solo, v. 30, n. 3, p. 391-399, 2006.

SOUZA JL; PEREIRA, VA. Importância multifuncional de coberturas mortas em canteiros de cenoura no sistema orgânico. Horticultura Brasileira 29: S4214-S4222, 2011.

SOUZA JL; RESENDE P. Manual de Horticultura Orgânica. 2 ed. Viçosa: Aprenda Fácil Editora, 843 p, 2006.

STRECK, N. A; et al. Modificações físicas causadas pelo mulching. Revista Brasileira de Agrometeorologia, v. 2, p. 131-142, 1994.

TAIZ, L.; et al. Fisiologia e desenvolvimento vegetal. 6. ed. Porto Alegre: Artmed, 858 p, 2017.

TROEH, F. R.; et al. Solos e fertilidade do solo. 6. ed. São Paulo: Andrei, 718 p, 2007.

VIEIRA, LUCIO SALGADO. Manual da ciência do solo: com ênfase aos solos tropicais. São Paulo, Ed. Agronômica Ceres, $2^{\circ}$ edição, 1988. 